\title{
Efeito de diferentes proporções de resíduo úmido de cervejaria sobre as características da carcaça de cordeiros terminados em confinamento
}

[Effect of different proportions of wet brewery residue on the carcass characteristics of feedlot finished lambs]

\author{
M.A. Brochier ${ }^{1}$, S. Carvalho ${ }^{2 *}$ \\ ${ }^{1}$ Aluna de pós-graduação - Feevale - Novo Hamburgo, RS \\ ${ }^{2}$ Centro Universitário Feevale \\ RS 239, 2755 \\ 93352-000 - Novo Hamburgo, RS
}

\begin{abstract}
RESUMO
Avaliou-se o efeito do uso de diferentes proporções de resíduo úmido de cervejaria sobre as características da carcaça de cordeiros terminados em sistema de confinamento. Foram utilizados 25 cordeiros, machos, não-castrados, da raça Texel, distribuídos aleatoriamente em cinco tratamentos compostos por proporções de $0 \%, 25 \%, 50 \%, 75 \%$ e $100 \%$ de substituição do alimento concentrado por resíduo úmido de cervejaria. Utilizou-se uma dieta composta de feno de Tifton- 85 e mistura concentrada em uma relação volumoso:concentrado de 40:60, com base na matéria seca (MS). O alimento concentrado foi constituído por milho desintegrado, farelo de soja, mistura mineral e resíduo úmido de cervejaria, sendo que suas proporções variaram de acordo com os tratamentos. Peso da carcaça quente, peso da carcaça fria, rendimento da carcaça quente, rendimento da carcaça fria, espessura da gordura subcutânea, pesos de quarto, paleta, costilhar e pescoço, bem como o comprimento de carcaça, a largura da perna e a profundidade da perna, diminuíram linearmente com o aumento da proporção de substituição do alimento concentrado por resíduo úmido de cervejaria.
\end{abstract}

Palavras-chave: ovino, confinamento, produção de carne, carcaça, resíduo de cervejaria

\begin{abstract}
The effect of the use of different proportions of wet brewery residue on the carcass characteristics of feedlot finished lambs was evaluated. Twenty-five non-castrated Texel male lambs were randomly allotted into five groups, consisting in the replacement of the concentrate by wet brewery residue at proportions of $0 \%, 25 \%, 50 \%, 75 \%$, and 100\%. Diet was composed by Tifton-85 hay and concentrate mixture, in a relation roughage:concentrate of 40:60, based on dry matter (DM). The concentrate was composed of ground corn, soybean meal, mineral mix, and wet brewery residue, and its proportions varied in accordance with the treatments. Weights and yields of hot and cold carcasses; subcutaneous fat thickness; weights of leg, shoulder, ribs and neck; as well as carcass length, leg width and leg depth showed a linear decrease of increase of wet brewery residue replacing the concentrate.
\end{abstract}

Keywords: sheep, feedlot, meat production, carcass, brewery residue

\section{INTRODUÇÃO}

A carne ovina é uma fonte de proteína de alto valor biológico, mas, para que possa competir com a de outras espécies, o produtor deve disponibilizar para o mercado carne proveniente do abate de animais jovens (cordeiros), criados de maneira adequada para obtenção de carcaças de primeira qualidade, pois o consumidor está cada vez mais exigente e busca produtos mais

Recebido em 30 de junho de 2008

Aceito em 3 de novembro de 2008

Autor para correspondência (corresponding author)

E-mail: sergiocarvalho@feevale.br 
saborosos e saudáveis. Assim, o cordeiro é a categoria animal que apresenta carne de melhor qualidade, por apresentar maciez, baixo teor de gordura e maior suculência, e é nesta fase que apresenta maiores rendimentos de carcaça e melhor eficiência de produção, devido a sua alta capacidade de crescimento (Pires et al., 2000).

A base de alimentação dos ovinos no Rio Grande do Sul é a pastagem natural, sendo os animais criados de maneira extensiva. Nesse sistema, tornase difícil obter animais jovens em condições de serem abatidos. Para tanto, é preciso modificar o meio ambiente, principalmente no que se refere à alimentação. De acordo com Carvalho et al. (1999), uma das alternativas eficazes é o confinamento. A terminação confinada possibilita variações na manipulação do sistema de produção, em conjunto com diversificações na alimentação oferecida aos cordeiros e no próprio manejo dos animais (Klein Júnior et al., 2008). No entanto, esta é uma prática que requer manejo especial, profundo conhecimento de nutrição animal e preços de mercado.

Uma vez que a nutrição constitui a base para o sucesso produtivo do sistema de confinamento, devem-se adotar estratégias que visem aumentar a eficiência de utilização dos nutrientes, aliada à redução dos custos com alimentação. $\mathrm{O}$ uso de dietas de baixo custo leva à busca por ingredientes mais baratos, os quais devem ser considerados não somente quanto à sua viabilidade econômica, mas também quanto ao desempenho animal (Mendes, 2006). Nesse sentido, resíduos agroindustriais têm sido utilizados na terminação de cordeiros em confinamento como forma de redução dos custos de alimentação, sem que ocorram quedas nos índices produtivos. Dentre esses resíduos, pode-se destacar o resíduo úmido de cervejaria, uma vez que é produzido em grande volume e, além disso, não apresenta problemas com a sazonalidade de sua produção (Brochier, 2007).

Este trabalho teve o objetivo de avaliar o efeito do uso de dietas contendo diferentes proporções de resíduo úmido de cervejaria sobre as características da carcaça de cordeiros terminados em sistema de confinamento.

\section{MATERIAL E MÉTODOS}

O local, a época, os animais, as instalações, os tratamentos, o manejo e as dietas experimentais foram apresentados por Brochier e Carvalho (2008).
Após cada abate, a carcaça foi pesada individualmente e, em seguida, resfriada por 18 horas em câmara frigorífica, à temperatura de $1^{\circ} \mathrm{C}$. Foram observadas as seguintes características em relação à carcaça dos cordeiros: peso da carcaça quente (PCQ), obtida mediante pesagem logo após o abate; peso da carcaça fria (PCF), obtida pela pesagem após a permanência de 18 horas em câmara fria a uma temperatura média de $1^{\circ} \mathrm{C}$; índice de quebra ao resfriamento (IQ), calculado pela diferença entre PCQ e PCF; rendimento de carcaça quente (RCQ), obtido da relação percentual entre peso vivo ao abate e PCQ; e rendimento de carcaça fria $(\mathrm{RCF})$ : relação percentual entre peso vivo ao abate e PCF. A carcaça foi separada ao meio, com o auxílio de uma serra elétrica, de forma simétrica, longitudinalmente, deixando a cauda no lado esquerdo. Na sua metade esquerda, foram tomadas as seguintes medidas e avaliações: comprimento da carcaça (CC), distância entre o bordo anterior da sínfise ísquio-pubiana e o bordo anterior da primeira costela em seu ponto médio; comprimento da perna (CP), distância entre o bordo anterior da sínfise ísquio-pubiana e a porção média dos ossos do tarso; profundidade do peito (PPEI), distância entre o dorso e o osso esterno, ou seja, entre a região das cruzes e a crista esternal em sua distância máxima; largura da perna (LP), distância entre os bordos interno e externo da parte superior da perna, em sua parte mais larga; profundidade da perna (PPER), maior distância entre o bordo proximal e distal da perna; e espessura de gordura de cobertura, determinada após medida em um ponto correspondente à porção média do terço distal do músculo Longissimus dorsi.

As metades direita e esquerda foram pesadas e separadas regionalmente nos seguintes cortes comerciais: pescoço, porção compreendida entre a secção atlanto-occipital e um corte oblíquo que passa entre a sétima vértebra cervical e a primeira dorsal, em direção à ponta do esterno e terminando na borda inferior do pescoço; paleta, membro anterior da carcaça, incluindo a musculatura da escápula, que na parte distal, a secção é feita na altura da porção média dos ossos do carpo; costilhar, parte da carcaça seccionada entre a última vértebra cervical e a primeira torácica e a última lombar e primeira sacra; e quarto ou perna, membro posterior da carcaça, seccionado na altura da articulação da última vértebra lombar e primeira sacra e na altura da porção média do tarso.

Após a separação, os diferentes cortes comerciais foram pesados e sua porcentagem calculada em relação ao peso da carcaça. A separação regional e 
as medidas nas carcaças foram realizadas segundo Osório et al. (1998).

O delineamento experimental utilizado foi o inteiramente ao acaso com cinco tratamentos e cinco repetições, sendo cada cordeiro considerado uma unidade experimental. Os dados foram submetidos a análises de variância e de regressão, com auxílio do pacote estatístico SÃS/1996. Os modelos foram selecionados com base nos coeficientes de determinação e na significância dos coeficientes de regressão, adotando-se o nível de $10 \%$ de probabilidade, utilizando-se o teste F.

\section{RESULTADOS E DISCUSSÃO}

Os valores para pesos e rendimentos de carcaça quente e fria, índice de quebra ao resfriamento e espessura de gordura subcutânea são apresentados na Tab.1. O aumento da proporção de substituição do alimento concentrado por resíduo úmido de cervejaria promoveu efeito linear decrescente $(\mathrm{P} \leq 0,01)$ sobre os rendimentos de carcaça quente e fria, o que pode ser explicado pela característica da dieta, pois a elevação da proporção de resíduo úmido de cervejaria em substituição ao alimento concentrado promoveu aumento no teor de FDN, o que leva a uma maior quantidade de conteúdo gastrintestinal no momento do abate e, consequentemente, pior rendimento de carcaça. Isto é semelhante ao resultado de Koesley et al. (1892), citado por Martinez et al. (2001), que dizem que o rendimento de carcaça depende principalmente de dois fatores: o conteúdo do aparelho digestivo e o grau de acabamento, variando o rendimento entre 40 e $53 \%$. Resultados semelhantes foram observados por Pires et al. (2006), que trabalharam com cordeiros confinados recebendo dietas com diferentes proporções de FDN $(25 \%, 31 \%, 37 \%$ e $43 \%$ ), e observaram valores de $46,4 \%, 43,9 \%$, $42,7 \%$ e $42,6 \%$, respectivamente, para rendimento de carcaça quente, e $45,0 \%, 42,6 \%$, $41,4 \%$ e $41,1 \%$, respectivamente, para rendimento de carcaça fria.

Tabela 1. Valores médios para peso vivo ao abate (PVA), peso carcaça quente (PCQ), peso carcaça fria $(\mathrm{PCF})$, rendimento carcaça quente $(\mathrm{RCQ})$, rendimento carcaça fria $(\mathrm{RCF})$, índice de quebra ao resfriamento (IQ) e espessura de gordura subcutânea (EG), em função da proporção de substituição do alimento concentrado por resíduo úmido de cervejaria

\begin{tabular}{|c|c|c|c|c|c|c|c|c|}
\hline & \multicolumn{5}{|c|}{ Proporção de resíduo de cervejaria } & \multirow{2}{*}{$\begin{array}{l}\text { Equação de regressão } \\
(\hat{Y})\end{array}$} & \multirow{2}{*}{$\mathrm{R}^{2}$} & \multirow{2}{*}{$\mathrm{CV}$} \\
\hline & 0 & 25 & 50 & 75 & 100 & & & \\
\hline PVA $(\mathrm{kg})$ & 28,00 & 28,20 & 26,80 & 28,48 & 22,12 & & & 20,71 \\
\hline PCQ (kg) & 13,33 & 13,64 & 12,35 & 12,78 & 9,21 & $14,04509-0,03606 * *$ RES & 0,18 & 23,21 \\
\hline PCF (kg) & 12,98 & 13,22 & 11,98 & 12,42 & 8,92 & $13,65020-0,03531 * *$ RES & 0,18 & 23,29 \\
\hline RCQ (\%) & 47,77 & 48,46 & 46,06 & 44,05 & 41,57 & $48,84574-0,06628 * * *$ RES & 0,39 & 6,84 \\
\hline RCF (\%) & 46,49 & 46,58 & 44,64 & 42,79 & 40,26 & $47,47071-0,065667 * * *$ RES & 0,39 & 6,89 \\
\hline IQ (\%) & 2,67 & 3,07 & 3,09 & 2,86 & 3,15 & & & 17,91 \\
\hline $\mathrm{EG}(\mathrm{mm})$ & 1,80 & 1,75 & 1,20 & 1,40 & 1,00 & $1,80936-0,00769 * \mathrm{RES}$ & 0,15 & 47,64 \\
\hline
\end{tabular}

$*, * *$ e ***: significativo a 10,5 e $1 \%$ de probabilidade, respectivamente, pelo teste $\mathrm{F}$.

RES: proporção de resíduo úmido de cervejaria da dieta.

Verificou-se redução linear $(\mathrm{P} \leq 0,05)$ no peso de carcaça quente e fria com a elevação do teor de resíduo na dieta, o que é explicado pela redução linear verificada no rendimento de carcaça e no menor valor numérico verificado no peso vivo dos cordeiros no momento do abate.

Quanto ao índice de quebra ao resfriamento, Martins (1997) enfatiza que esse índice indica o percentual de peso que é perdido durante o resfriamento da carcaça, em função de alguns fatores, como perda de umidade e reações químicas que ocorrem no músculo. Assim, quanto menor esse percentual, maior é a probabilidade de a carcaça ter sido manejada e armazenada de maneira adequada. Neste experimento, o índice de quebra ao resfriamento não foi influenciado pela proporção de inclusão do resíduo de cervejaria, apresentando valor médio de $2,9 \%$, semelhante ao resultado de Brito et al. (2005), os quais citam que, de forma geral, os valores para os índices de quebra ao resfriamento estão em torno de $2,5 \%$. Perdas decorrentes do resfriamento semelhantes às deste trabalho foram verificadas por Almeida Jr. et al. (2004), que avaliaram proporções de substituição de grãos secos de milho pela silagem de grãos úmidos de milho na dieta de cordeiros criados e 
terminados em creep feeding, abatidos com peso vivo médio de $26,31 \mathrm{~kg}$ e com peso médio de carcaça quente de $13,36 \mathrm{~kg}$, e observaram valor médio para índice de quebra ao resfriamento de $2,9 \%$.

Quanto à espessura de gordura subcutânea, verifica-se que houve diminuição linear $(\mathrm{P} \leq 0,1)$ com o aumento da proporção de inclusão do resíduo úmido de cervejaria, possivelmente devido à redução do teor energético das dietas, o que levou à menor deposição de gordura na carcaça. Garcia et al. (2003), ao trabalharem com cordeiros alimentados com diferentes teores de energia em creep feeding, também observaram redução linear na espessura de gordura, relacionada com a diminuição da energia da dieta. Silva e Pires (1998) encontraram valores de $1,75 \mathrm{~mm}$ para animais abatidos com peso vivo médio de $28 \mathrm{~kg}$, resultado este que está de acordo com o verificado para espessura de gordura subcutânea dos cordeiros dos tratamentos com 0 e $25 \%$ de substituição do alimento concentrado pelo resíduo úmido de cervejaria, sendo que esses animais também foram abatidos com $28 \mathrm{~kg}$ de peso vivo.

Na Tab. 2 são apresentados os dados referentes aos pesos e às proporções dos cortes comerciais da carcaça dos cordeiros. A análise de regressão mostrou influência significativa da proporção de substituição do alimento concentrado por resíduo úmido de cervejaria sobre o peso do quarto, paleta, costilhar e pescoço, que diminuiu linearmente com o aumento da proporção de resíduo nas dietas. Esse comportamento está associado ao maior peso de abate e rendimento de carcaça dos animais alimentados com menor proporção de resíduo, o que proporcionou carcaças mais pesadas e, consequentemente, maior peso dos cortes comerciais avaliados.

Tabela 2. Valores médios para pesos e proporções de quarto (QUA), paleta (PAL), costilhar (COST) e pescoço (PESC), em função da proporção de substituição do alimento concentrado por resíduo úmido de cervejaria

\begin{tabular}{|c|c|c|c|c|c|c|c|c|}
\hline & \multicolumn{5}{|c|}{ Proporção de resíduo de cervejaria } & \multirow{2}{*}{$\begin{array}{l}\text { Equação de regressão } \\
(\hat{Y})\end{array}$} & \multirow{2}{*}{$\mathrm{R}^{2}$} & \multirow{2}{*}{$\mathrm{C} \mathrm{V}$} \\
\hline & 0 & 25 & 50 & 75 & 100 & & & \\
\hline QUA (kg) & 4,404 & 4,385 & 3,906 & 4,190 & 3,094 & $4,54963-0,01117 *$ RES & 0,16 & 23,73 \\
\hline QUA (\%) & 33,99 & 33,120 & 32,71 & 33,66 & 34,64 & & & 4,88 \\
\hline PAL (kg) & 2,624 & 2,652 & 2,250 & 2,524 & 1,834 & 2,70969-0,00674**RES & 0,16 & 23,99 \\
\hline PAL (\%) & 20,19 & 20,082 & 18,97 & 20,35 & 20,61 & & & 8,90 \\
\hline COST (kg) & 4,754 & 4,972 & 4,194 & 4,576 & 3,198 & $5,01654-0,01379 *$ RES & 0,19 & 24,89 \\
\hline COST $(\%)$ & 36,57 & 37,625 & 34,87 & 36,77 & 35,72 & & & 4,84 \\
\hline PESC (kg) & 1,192 & 1,215 & 0,930 & 1,130 & 0,778 & $1,22524-0,00359 * *$ RES & 0,20 & 26,01 \\
\hline $\operatorname{PESC}(\%)$ & 9,17 & 9,177 & 7,90 & 9,18 & 8,75 & & & 14,91 \\
\hline
\end{tabular}

* e **, significativo a 10 e $5 \%$ de probabilidade, respectivamente, pelo teste $\mathrm{F}$.

RES: proporção de resíduo úmido de cervejaria da dieta.

Quanto à proporção dos cortes comerciais, não houve diferença entre os tratamentos. Valores semelhantes foram encontrados por Frescura (2003), que trabalhou com cordeiros cruzas Ile de France $x$ Texel confinados e abatidos com $28,3 \mathrm{~kg}$ de peso vivo e verificou valores médios para as proporções de quarto, paleta, costilhar e pescoço de $34,0 \%, 19,5 \%, 37,3 \%$ e $9,2 \%$, respectivamente. Os resultados do presente trabalho confirmam os obtidos por Pires et al. (2006), que trabalharam com cordeiros cruza Ile de France $\mathrm{x}$ Texel, confinados e alimentados com dietas contendo diferentes proporções de FDN e abatidos com $30 \mathrm{~kg}$ de peso vivo, e não observaram diferença significativa entre os tratamentos, tendo os autores verificado valores médios de $34,0 \%$ para quarto, $20,2 \%$ para paleta, $37,0 \%$ para costilhar e $9,4 \%$ para pescoço.

Os valores médios para comprimento de carcaça, comprimento de perna, profundidade de peito, largura de perna e profundidade de perna são apresentados na Tab. 3. Não houve efeito da proporção de substituição do alimento concentrado por resíduo úmido de cervejaria sobre os parâmetros comprimento de perna e profundidade de peito. No entanto, houve efeito linear decrescente do aumento do resíduo úmido de cervejaria sobre o comprimento de carcaça, largura e profundidade da perna. 
Tabela 3. Valores médios, em $\mathrm{cm}$, para comprimento de carcaça (CCARC), comprimento de perna (CPERN), profundidade de peito (PPEIT), largura de perna (LPERN) e profundidade de perna (PPERN), em função da proporção de substituição do alimento concentrado por resíduo úmido de cervejaria

\begin{tabular}{|c|c|c|c|c|c|c|c|c|}
\hline & \multicolumn{5}{|c|}{ Proporção de resíduo de cervejaria } & \multirow{2}{*}{$\begin{array}{c}\text { Equação de regressão } \\
(\hat{Y})\end{array}$} & \multirow{2}{*}{$\mathrm{R}^{2}$} & \multirow{2}{*}{$\mathrm{C} \mathrm{V}$} \\
\hline & 0 & 25 & 50 & 75 & 100 & & & \\
\hline CCARC & 53,40 & 53,52 & 51,80 & 52,58 & 48,64 & $54,04034-0,04144 * *$ RES & 0,21 & 5,71 \\
\hline CPERN & 34,26 & 31,77 & 32,56 & 32,02 & 31,74 & & & 7,35 \\
\hline PPEIT & 21,82 & 20,97 & 20,96 & 20,84 & 20,32 & & & 8,47 \\
\hline LPERN & 8,90 & 8,65 & 8,40 & 8,38 & 7,30 & $9,02196-0,01390 * *$ RES & 0,26 & 10,38 \\
\hline PPERN & 13,68 & 13,47 & 13,14 & 12,82 & 11,88 & $13,84570-0,01698 * *$ RES & 0,20 & 9,81 \\
\hline
\end{tabular}

** Significativo a $5 \%$ de probabilidade, pelo teste $\mathrm{F}$.

RES: proporção de resíduo úmido de cervejaria da dieta.

Garcia et al. (1999), ao avaliarem as características de carcaças de cordeiros mestiços Texel, confinados sob diferentes relações volumoso:concentrado, recebendo dietas isoprotéicas (18\% PB) e abatidos com 30 e $34 \mathrm{~kg}$ de peso vivo, obtiveram valores médios para comprimento de carcaça e comprimento de perna de 51,4 e $33,60 \mathrm{~cm}$, respectivamente. Esses valores são bem próximos aos do presente trabalho, que foram de 51,99 e $32,50 \mathrm{~cm}$.

Pires et al. (2006), ao trabalharem com cordeiros confinados que recebiam dietas com diferentes proporções de FDN, obtiveram resultados para comprimento de carcaça de $55,24 \mathrm{~cm}$, comprimento de perna de $35,28 \mathrm{~cm}$, profundidade de peito de $23,29 \mathrm{~cm}$ e largura de perna de $9,34 \mathrm{~cm}$, resultados esses ligeiramente maiores que os do presente trabalho, o que possivelmente pode ser explicado pelo peso vivo final dos cordeiros $(30 \mathrm{~kg})$, também mais elevado.

\section{CONCLUSÕES}

Proporções crescentes de resíduo úmido de cervejaria na dieta influenciam negativamente o peso da carcaça quente, o peso da carcaça fria, o rendimento da carcaça quente, o rendimento de carcaça fria, a espessura da gordura subcutânea, os pesos do quarto, paleta, costilhar e pescoço, o comprimento da carcaça, a largura e a profundidade da perna, de cordeiros da raça Texel, terminados em sistema de confinamento.

\section{REFERÊNCIAS BIBLIOGRÁFICAS}

ALMEIDA Jr., G.A.; COSTA, C.; MONTEIRO, A.L.G. et al. Desempenho, características de carcaça e resultado econômico de cordeiros criados em creep feeding com silagem de grãos úmidos de milho. Rev. Bras. Zootec., v.33, p.1048-1059, 2004.

BRITO, R.A.M.; DIAS, M.J.; DIAS, D.S.O. et al. Características da carcaça e composição centesimal da carne de borregos de dois genótipos criados em confinamento. In: CONGRESSO DE PESQUISA, ENSINO E EXTENSÃO, 2., 2005, Goiânia. Anais... Goiânia: UFG, 2005. CD-ROM.

BROCHIER, M.A. Aproveitamento de resíduo úmido de cervejaria na alimentação de cordeiros confinados em fase de terminação. 2007. 120f. Dissertação (Mestrado) - Centro Universitário Feevale, Novo Hamburgo.

BROCHIER, M.A.; CARVALHO, S. Consumo, ganho de peso e análise econômica da terminação de cordeiros em confinamento com dietas contendo diferentes proporções de resíduo úmido de cervejaria. Arq. Bras. Med. Vet. Zootec, v.60, p.1205-1212, 2008.

CARVALHO, S.; PIRES, C.C.; PERES, J.R. et al. Desempenho de cordeiros machos inteiros, machos castrados e fêmeas, alimentados em confinamento. Cienc. Rural, v.29, p.129-133, 1999.

FRESCURA, R.B.M. Produção de cordeiros em pastagem cultivada de azevém (Lolium multiflorum Lam.) e em confinamento. 2003. 75f.. Dissertação (Mestrado) - Departamento de Zootecnia, Universidade Federal de Santa Maria, Santa Maria.

GARCIA, C.A.; MONTEIRO, A.L.G.; COSTA, C. et al. Medidas objetivas e composição tecidual da carcaça de cordeiros alimentados com diferentes níveis de energia em creep feeding. Rev. Bras. Zootec., v.32, p.1380-1390, 2003.

GARCIA, C.A.; SILVA SOBRINHO, A.G.; GASTALDI, K.A. Influência das diferentes 
relações volumoso:concentrado e pesos de abate de cordeiros confinados. In: REUNIÃO ANUAL DA SOCIEDADE BRASILEIRA DE ZOOTECNIA, 36., 1999, Porto Alegre. Anais... Porto Alegre: SBZ, 1999. p.339.

KLEIN JÚNIOR, M.H.; SIQUEIRA, E.R.; ROÇA, R.O. Composição tecidual e qualidade da gordura na carne de cordeiros castrados e não castrados confinados sob dois fotoperíodos. Arq. Bras. Med. Vet. Zootec., v.60, p.461-469, 2008.

KOESLEY, F.; OROZCO, A.M.; ACOSTA, G. et al. Producción de carne: manuales para producción agropecuária, 1982. 64p.

MARTINEZ, D.E.; NUÑEZ, F.A.G.; GARCÍA, A.M. et al. Caracterización de canales de borregos alimentados con desechos de papel. Rev. Bras. Acroc., v.7, p.50-53, 2001.

MARTINS, V.R.A. Utilização de dejetos de suínos em dietas de ovinos em sistema de confinamento. 1997, 51f. Dissertação (Mestrado) - Departamento de Zootecnia, Universidade Federal de Lavras, Lavras.

MENDES, C.Q. Importância da nutrição de ovinos criados em sistemas intensivos de produção. Disponível em: $<$ http://www.farmpoint.com.br $>$. Acessado em: 3 jun. 2006.

OSÓRIO, J.C.S.; OSÓRIO, M.T.M.; JARDIM, P.O.C. et al. Métodos para avaliação da produção de carne ovina, in vivo, na carcaça e na carne. Pelotas: Editora Universitária, 1998. $107 \mathrm{p}$.

PIRES, C.C.; SILVA, L.F.; SCHLICK, F.E. et al. Cria e terminação de cordeiros confinados. Cienc. Rural, v.30, p.875-880, 2000.

PIRES, C.C.; GALVANI, D.B.; CARVALHO, $\mathrm{S}$. et al. Características da carcaça de cordeiros alimentados com dietas contendo diferentes níveis de fibra em detergente neutro. Rev. Bras. Zootec., v.35, p.2058-2065, 2006.

SILVA, L.F.; PIRES, C.C. Estudo da composição e características da carcaça de cordeiros. In: REUNIÃO ANUAL DA SOCIEDADE BRASILEIRA DE ZOOTECNIA, 35., 1998, Botucatu. Anais..., Botucatu: SBZ, 1998. CD-ROM. 